\title{
Middle East respiratory syndrome coronavirus: epidemiology and disease control measures
}

\author{
This article was published in the following Dove Press journal: \\ Infection and Drug Resistance \\ 3 November 2014 \\ Number of times this article has been viewed
}

\author{
Jaffar A Al-Tawfiq ${ }^{1,2}$ \\ Ziad A Memish ${ }^{3,4}$ \\ 'Johns Hopkins Aramco Healthcare, \\ Dhahran, Saudi Arabia; ${ }^{2}$ Indiana \\ University School of Medicine, \\ Indianapolis, IN, USA; ${ }^{3}$ Ministry \\ of Health, ${ }^{4}$ Alfaisal University, \\ Riyadh, Saudi Arabia
}

Correspondence: Ziad A Memish Ministry of Health, College of Medicine, Alfaisal University, PO Box 54I46, Riyadh, II5I4, Saudi Arabia Tel +966505 483515

Email zmemish@yahoo.com

\begin{abstract}
The emergence of Middle East respiratory syndrome coronavirus (MERS-CoV) infection in 2012 resulted in an increased concern of the spread of the infection globally. MERS-CoV infection had previously caused multiple health-care-associated outbreaks and resulted in transmission of the virus within families. Community onset MERS-CoV cases continue to occur. Dromedary camels are currently the most likely animal to be linked to human MERS-CoV cases. Serologic tests showed significant infection in adult camels compared to juvenile camels. The control of MERS-CoV infection relies on prompt identification of cases within health care facilities, with institutions applying appropriate infection control measures. In addition, determining the exact route of transmission from camels to humans would further add to the control measures of MERS-CoV infection.
\end{abstract}

Keywords: MERS, Middle East respiratory syndrome coronavirus, epidemiology, control measures, transmission, Saudi Arabia

\section{Introduction}

Middle East respiratory syndrome coronavirus (MERS-CoV) was initially identified from a 60-year-old Saudi man who was admitted to a private hospital in Jeddah (Figure 1) on June 13, 2012, with history of fever, cough, expectoration, and shortness of breath. ${ }^{1}$ He subsequently died 11 days later from progressive respiratory failure. ${ }^{1}$ A sputum sample tested negative for common respiratory viruses (influenza A and B viruses, parainfluenza virus types 1 to 3, respiratory syncytial virus, and adenovirus). Inoculation of sputum in LLC-MK2 and Vero cells resulted in viral cytopathic changes. ${ }^{1}$ The virus was later identified as a new coronavirus and called Human Coronavirus Erasmus Medical Center (HCoV-EMC). ${ }^{1}$ A subsequent patient from Qatar, a 49-year-old man, was diagnosed in September 2012 with the novel coronavirus (MERS-CoV) and he was transported to the United Kingdom for intensive care. ${ }^{2}$ The isolated viruses from the Saudi and the Qatari cases were 99.5\% identical. ${ }^{2}$ Subsequently, the virus was designated as MERS-CoV instead of $\mathrm{HCoV}$-EMC according to the Coronavirus Study Group. ${ }^{3}$ Retrospective analysis of stored samples from an outbreak in Zarqa, Jordan of a cluster of hospital cases of severe respiratory illness dating back to April 2012 confirmed MERS-CoV as the cause of the outbreak. ${ }^{4}$ Since the initial description and as of July 14, 2014, a total of 834 laboratory-confirmed cases of infection with MERS-CoV including 288 (34.5\%) deaths were reported to the World Health Organization (WHO). ${ }^{5}$ In this review, we highlight the epidemiology and disease control measures of MERS-CoV. We reviewed the available literature from the beginning of June 2012 to June 2014 utilizing PubMed and Google Scholar. 


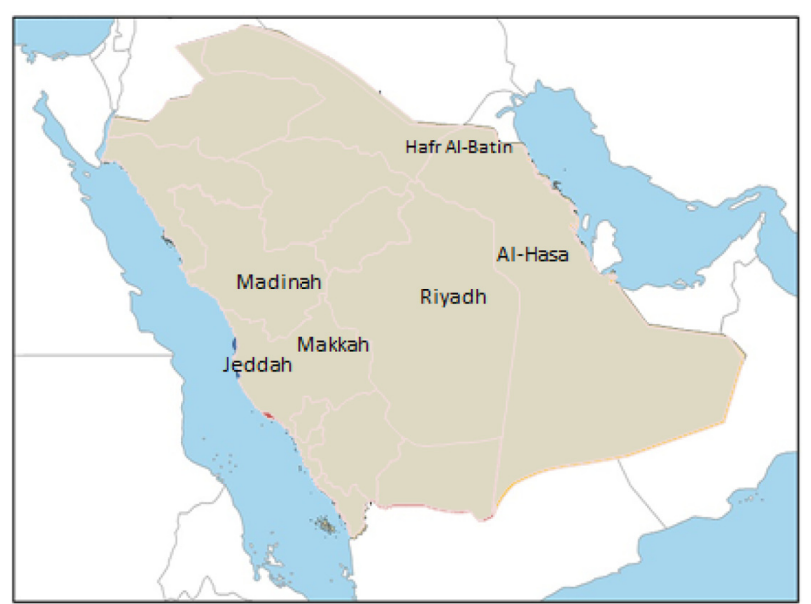

Figure I A map of the Kingdom of Saudi Arabia showing the main cities described in this paper: Riyadh (the capital); Al-Hasa (20I3 outbreak); Jeddah (20I4 outbreak); Hafr Al-Batin (community cluster); and the holy Cities (Makkah and Madinah).

\section{Epidemiology}

The knowledge about the epidemiology of MERS-CoV was expanded after exploring the large hospital outbreak in Al-Hasa, Saudi Arabia. ${ }^{6}$ The initial occurrence of MERS-CoV was thought to have particular predominance for male patients and those with comorbid diseases. ${ }^{6-8}$ The male-to-female ratio was between $2.8: 1$ to $3.3: 1 .^{6,7}$ This male predominance might have been related to the nature of the outbreak. Initial cases were reported among elderly patients with a median age of 56 years. A summary of demographics of major MERS-CoV studies is shown in Table 1.6,7,9-12 During the second quarter of 2014 (April-May) there was an unusual increase in the number of reported cases from Saudi Arabia. From April 11 to June 9, 2014, a total of 515 cases of MERS$\mathrm{CoV}$ were reported to WHO. ${ }^{11}$ A total of 113 cases were reported on June 2, 2014 retrospectively to WHO. These cases are summarized in Table 1. Of the initial cases, there were eleven cases of childhood MERS-CoV and all but two of the cases were asymptomatic. ${ }^{13}$

\section{Change of MERS-CoV case demography over time}

Early in the course of MERS-CoV, the initial cases were more common in males than females and later the male-to-female ratio was less pronounced. The initial predominance of male cases may be due to the characteristics of the outbreak in AlHasa (Figure 1). ${ }^{6}$ As more cases were identified, this predominance was lost and a more balanced sex distribution started to reflect the true distribution of the cases. In an initial analysis of the first 179 cases, there were some differences between primary (sporadic and index cases) and secondary cases. ${ }^{14}$ Primary cases were more likely to be male ( $80 \%$ versus $58 \%$ ), and to be older (median age: 58 years versus 48 years). Health care workers constituted $35 \%$ of secondary cases versus $3 \%$ of the primary cases. ${ }^{14}$ When comparing the Al-Hasa outbreak in 2013 with the most recent cases in April-May 2014, the Al-Hasa cases were older in age ( 56 years versus 46 years), there were more male cases (male-to-female ratio 2.8:1 versus 1.4:1), there were more severe cases (100\% versus $44.5 \%)$, and there was a higher mortality rate $(65 \%$ versus $28.3 \%$ ) (Table 1$){ }^{6,7,9-12}$

\section{Seasonality pattern of MERS-CoV}

The occurrence of the majority of cases seems to follow a seasonal distribution: April 2012 (Zarqa public health hospital, Jordan), ${ }^{4}$ April-May 2013 (Al-Hasa outbreak), ${ }^{6}$ and April-May 2014 (Jeddah and United Arab Emirates outbreak). ${ }^{14}$ The occurrence of the cases in the spring raises the possibility of seasonal cycles of MERS-CoV, as was suggested. ${ }^{15}$ This notion is further substantiated by the fact that camels give birth in March (spring) and that MERS-CoV is more common in adult camels ( $>2$ years old) than young camels (Table 2). ${ }^{6,79-12,16-19}$ The difference in the positivity rate was not statistically significant in three studies. ${ }^{16-19}$

\section{Asymptomatic cases}

The initial cases of MERS-CoV were detected among patients admitted with severe community-acquired pneumonia and the

Table I A summary of demographics of major MERS-CoV studies

\begin{tabular}{|c|c|c|c|c|c|c|}
\hline $\begin{array}{l}\text { Number } \\
\text { of cases }\end{array}$ & $\begin{array}{l}\text { Median age } \\
\text { (range) years }\end{array}$ & $\begin{array}{l}\text { Male-to- } \\
\text { female ratio }\end{array}$ & $\begin{array}{l}\text { Percentage } \\
\text { asymptomatic }\end{array}$ & $\begin{array}{l}\text { Percentage } \\
\text { severe cases }\end{array}$ & $\begin{array}{l}\text { Case } \\
\text { fatality rate (\%) }\end{array}$ & Reference \\
\hline 23 & $56(24-94)$ & $2.8: 1$ & 0 & 100 & 65 & 6 \\
\hline 47 & NA & 3.3:1 & 0 & 100 & 60 & 7 \\
\hline 133 & NA & $1.5: 1$ & 13.5 & 86.5 & 45 & 9 \\
\hline 161 & $50(14-94)$ & $1.8: 1$ & II.I & 63.4 & - & 10 \\
\hline 402 & $46(0.75-94)$ & I.4:I & 28.6 & 44.5 & 28.3 & 11 \\
\hline 113 & 41 (0.25-89) & $1.3: 1$ & 28.9 & NA & 30 & 12 \\
\hline
\end{tabular}

Abbreviations: MERS-CoV, Middle East respiratory syndrome coronavirus; NA, not available. 
Table 2 A summary of the serology results of juvenile and adult ( $>2$ years old) camels in different studies

\begin{tabular}{llllllll}
\hline Juvenile & & & Adult & & P-value & Country & Reference \\
Total tested & Percent positive & & Total tested & Percent positive & & & \\
\hline 65 & 72 & 245 & 95 & 14 & 0.0001 & Saudi Arabia & 16 \\
8 & 13 & 97 & 97 & 1.0 & Spain & 17 \\
31 & 93 & 157 & 54 & 0.325 & Ethiopia & 18 \\
46 & 30 & 158 & 95 & 0.007 & Tunisia & 18 \\
104 & 55 & 98 & 91 & 0.0001 & Saudi Arabia & 19 \\
21 & 76 & 23 & 92 & 0.237 & Saudi Arabia & 19 \\
56 & 72 & 26 & & 0.04 & Saudi Arabia & 19 \\
\hline
\end{tabular}

majority of them required intensive care unit admission. ${ }^{6,7}$ Subsequently, individuals with mild or no symptoms were reported. Contact investigation of cases of MERS-CoV resulted in the identification of asymptomatic cases (Table 1). ${ }^{6,7,9-12}$ The rate of positivity of contacts by polymerase chain reaction was 0\%-15.4\% ${ }^{4,20-23}$ The largest screening came from Saudi Arabia and the rate of positivity among health care workers and family contacts was $1.12 \%$ and $3.6 \%$, respectively. ${ }^{20}$

\section{Transmission}

Understanding the epidemiology and transmission of MERS-CoV requires the classifications of cases into: sporadic (community-onset), intra-familial transmission, and health-care-related transmission. The WHO MERS-CoV Research Group defined sporadic and index cases as meeting one of the following criteria: no history of contact with other MERS-CoV cases, occurring in an area with no previous cases within the last 2 months, or the first or index case in a cluster. ${ }^{10}$

\section{Sporadic: animal to human transmission}

Of all the cases reported to WHO, only $25 \%$ of the cases are considered as primary cases. ${ }^{24}$ The acquisition of MERS-CoV in these sporadic cases could be from animal contact. The data suggest that camels are the likely source of MERS-CoV. Previous studies showed a high rate of positive serology in dromedary camels in multiple countries including: the Kingdom of Saudi Arabia (KSA), Oman, Canary Islands, Egypt, Qatar, the United Arab Emirates, Jordan, and African countries. ${ }^{17,18,25-33}$ A summary of the number of tested camels and the percentage rates are shown in Figure 2.

A stronger evidence of the connection comes from the detection of MERS-CoV by polymerase chain reaction from camels from Jeddah, KSA, ${ }^{34,35}$ and in Qatar. ${ }^{25}$ The presence of a few genomic variants of MERS-CoV in dromedary camels suggests the transmission of MERS-CoV from camels to humans. ${ }^{36}$ The route of transmission of MERS$\mathrm{CoV}$ from camels to humans remains to be identified.

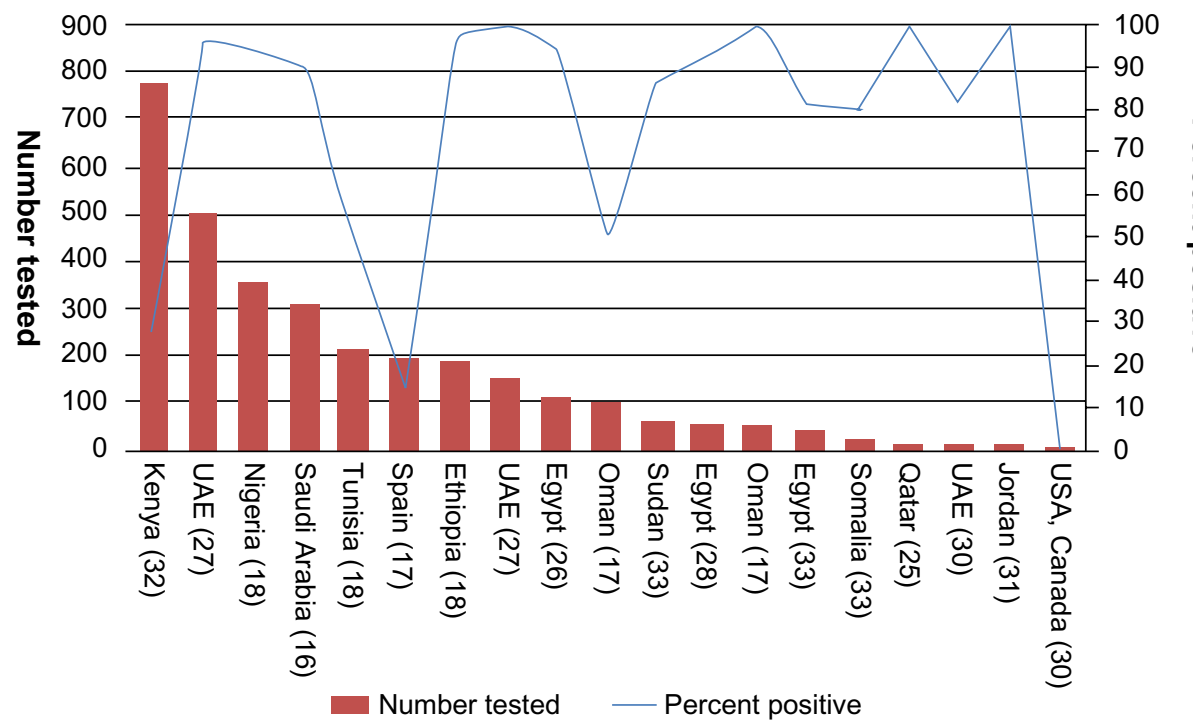

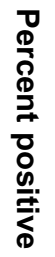

Figure $2 \mathrm{~A}$ graph showing the total number of tested camels and the percentage positive.

Note: $\mathrm{x}$-axis shows the country of testing (reference number).

Abbreviation: UAE, United Arab Emirates. 
Camels' milk may play a role as MERS-CoV was detected in $41.7 \%$ of 12 tested camel milk samples which were collected according to the custom of the people in the region. ${ }^{37}$ Whether there was a contamination during the process of milk collection or not is not known. There was variation in the number of cases that reported camel contact, with the highest proportion of contact coming from Oman and the United Arab Emirates. ${ }^{38}$ Since not all cases have contact with camels, another source may exist.

People working with camels such as farm workers, slaughterhouse workers, and veterinarians may be at higher risk of MERS-CoV infection than other people. ${ }^{39}$ Goats, cows, sheep, water buffalo, and birds were negative for antibodies to MERS-CoV. ${ }^{16,31,39}$ Thus, so far no other animal link has been identified apart from camels and bats. ${ }^{40,41}$

\section{Community outbreaks (intra-familial)}

Community outbreaks of MERS-CoV have been limited to intra-familial transmission. In an initial report of a family cluster, 28 individuals lived in an extended household and four of them tested positive for MERS-CoV, including the index case. ${ }^{42}$ The secondary attack rate in this cluster was $11 \%{ }^{43}$ In a second family cluster, two brothers tested positive for MERS-CoV from eight contacts of an index case $^{42}$ with an attack rate of $13 \%{ }^{43,44}$

In a third community cluster occurring in an extended family in Hafr Al-Batin (Figure 1), an index case was closely associated with five additional MERS-CoV cases and one of the secondary contacts was associated with another four cases. ${ }^{45}$ The secondary attack rate was $19.4 \% .{ }^{45}$ However, the calculated rate of secondary transmissions among family contacts was $3.03 \%$ in a large screening of 462 family members. ${ }^{19}$ Intra-familial transmission of MERS-CoV is thought to be secondary to person-to-person transmission and is limited to close contacts. ${ }^{43}$ The presence of another source of infection among family contacts could not be excluded as phylogenetic analysis of the Hafr Al-Batin cluster showed that two of the infected contacts could not have been directly infected from the index patient. ${ }^{45}$ Being a member of the same family may result in exposure to the same unknown source of infection.

\section{Health-care-associated transmission}

It is known that a large proportion of MERS-CoV cases occurred in the health care setting. The first identified hospital outbreak was in Zarqa, Jordan. ${ }^{4}$ This outbreak was identified retrospectively after the identification of the first MERS-CoV case in Jeddah, Saudi Arabia. The Zarqa outbreak involved eleven patients and eight of them were health care workers. ${ }^{4}$ MERS-CoV was retrospectively confirmed in two patients. ${ }^{4}$ Further analysis showed that nine (7.2\%) of 124 contacts in this outbreak were positive by serology. ${ }^{46}$

The Al-Hasa outbreak in 2013 provided valuable information about MERS-CoV transmission in the health care setting. ${ }^{6}$ The outbreak initially started in a hemodialysis unit in a private hospital in Al-Hasa and subsequently involved an additional three hospitals. ${ }^{6}$ The transmission was thought to be person-to-person in 21 of 23 cases and occurred in the hemodialysis unit, the intensive care unit, and/or the in-patient units. ${ }^{6}$ The transmission was secondary to droplet as well as direct or indirect contact. Further phylogenetic analysis of this outbreak showed that only eight of the 13 epidemiologic transmissions were related, suggesting multiple introductions of MERS-CoV in that outbreak. ${ }^{47}$ The most recent health care transmission occurred in Jeddah, Saudi Arabia in April-May 2014. There was no change in the virus transmission or mutation. ${ }^{48}$ Near full genome sequence analyses of three viruses from the early phase of the Jeddah outbreak were highly similar but not identical, with no genome insertions or deletions. ${ }^{48}$ Most of the human-to-human infections were in the health care setting and $25 \%$ of all cases were health care workers. ${ }^{49}$ In April 2014, another health-care-associated cluster was reported from Al-Ain, United Arab Emirates and resulted in infection of 16 health care workers of the 23 total cases. ${ }^{50}$ The recent increase in the number of cases of MERS-CoV in April-May 2014 showed that 75\% of the cases were secondary cases and that most of these cases were health care workers who acquired the infection in the health care setting. ${ }^{24}$ In the most recent outbreak in Saudi Arabia, of the 402 cases reported in June 2014, at least 25\% were health care workers. ${ }^{11}$ One study showed that health care workers who contracted MERS-CoV were involved in aerosol generating procedures such as intubation, airway suctioning, and sputum induction. ${ }^{49-51}$

\section{Travel related}

With the emergence of MERS, there was a great concern for the possible transmission of MERS-CoV during travel and during the annual Pilgrimage. A number of sporadic cases were reported in different countries where these cases originated in that area. Travel-associated infection was reported in Greece, Jordan, Malaysia, and the Philippines; ${ }^{24}$ the United Kingdom, France, Tunisia, Italy, Egypt, the United States, and the Netherlands. ${ }^{52-57}$ Only limited human-to-human transmission of travel-related cases was reported in France and the 
United Kingdom. ${ }^{21,22}$ The annual Hajj in 2012 and 2013 was not associated with any MERS-CoV cases. ${ }^{58-61}$

\section{MERS-CoV disease control measures}

Understanding the route of transmission of MERS-CoV and the pattern of transmission of the disease is important for control and prevention. Currently, as mentioned above, the pattern of the disease transmission will dictate the methods for prevention. Sporadic cases are thought to be secondary to animal exposure, mostly related to camels. The WHO advises people at risk of acquiring MERS-CoV to avoid contact with camels, to practice good hand hygiene, and to avoid drinking raw milk or eating contaminated food unless it is properly washed, peeled, or cooked. ${ }^{24}$

Since most of the cases occur in the health care setting, it is prudent that all health care workers practice appropriate infection control measures when taking care of patients with suspected or confirmed MERS-CoV. Specifically, health care workers should apply standard precautions consistently with all patients. ${ }^{24}$ The application of droplet precautions are needed when providing care to patients with symptoms of acute respiratory infection. ${ }^{5}$ The addition of contact precautions and eye protection is required when caring for suspected or confirmed MERS-CoV infection. ${ }^{5}$ During aerosol generating procedures, airborne infection isolation precautions should be applied. ${ }^{5}$ The United States Centers for Disease Control and Prevention continues to recommend the use of airborne infection isolation precautions with all patients. ${ }^{62,63}$

As far as travel is concerned, WHO does not restrict travel to countries in the Middle East with cases of MERS-CoV. ${ }^{24}$ For the Hajj and Umrah, the Saudi Ministry of Health recommended that people at increased risk of MERS-CoV infection and its complications should postpone their Hajj. These people include: certain age groups ( $<12$ years, and $\geq 65$ years), individuals with chronic diseases (heart disease, kidney disease, respiratory disease, and diabetes), and those with immune deficiency, malignancy, terminal illnesses, or pregnancy. ${ }^{64}$

\section{Conclusion}

The epidemiology and the transmission pattern of MERS-CoV to date indicate that the majority of cases occur in the health care setting. Strengthening the infection control measures in the health care setting is of great importance. Since about $25 \%$ of cases are community based, there is a real need to further prevent the animal-to-human transmission of MERS-CoV. It is also important to further delineate the transmission routes and the presence of any other animal or intermediate hosts.

\section{Disclosure}

The authors report no conflicts of interest in this work.

\section{References}

1. Zaki AM1, van Boheemen S, Bestebroer TM, Osterhaus AD, Fouchier RA. Isolation of a novel coronavirus from a man with pneumonia in Saudi Arabia. N Engl J Med. 2012;367(19):1814-1820.

2. Bermingham A, Chand MA, Brown CS, et al. Severe respiratory illness caused by a novel coronavirus, in a patient transferred to the United Kingdom from the Middle East, September 2012. Euro Surveill. 2012;17(40):20290.

3. de Groot RJ, Baker SC, Baric RS, et al. Middle East respiratory syndrome coronavirus (MERS-CoV): announcement of the Coronavirus Study Group. J Virol. 2013;87(14):7790-7792.

4. Hijawi B, Abdallat M, Sayaydeh A, et al. Novel coronavirus infections in Jordan, April 2012: epidemiological findings from a retrospective investigation. East Mediterr Health J. 2013;19 Suppl 1:S12-S18.

5. World Health Organization. Middle East respiratory syndrome coronavirus (MERS-CoV) - update. Geneva: World Health Organization; 2014. Available from: http://www.who.int/csr/don/2014_07_14_mers/en/. Date accessed July 16, 2014.

6. Assiri A, McGeer A, Perl TM, et al; KSA MERS-CoV Investigation Team. Hospital outbreak of Middle East respiratory syndrome coronavirus. N Engl J Med. 2013;369(5):407-416.

7. Assiri A, Al-Tawfiq JA, Al-Rabeeah AA, et al. Epidemiological, demographic, and clinical characteristics of 47 cases of Middle East respiratory syndrome coronavirus disease from Saudi Arabia: a descriptive study. Lancet Infect Dis. 2013;13(9):752-761.

8. Al-Tawfiq JA, Assiri A, Memish ZA. Middle East respiratory syndrome novel corona MERS-CoV infection. Epidemiology and outcome update. Saudi Med J. 2013;34(10):991-994.

9. Penttinen PM, Kaasik-Aaslav K, Friaux A, et al. Taking stock of the first 133 MERS coronavirus cases globally - Is the epidemic changing? Euro Surveill. 2013;18(39). pii: 20596.

10. The Who Mers-Cov Research Group. State of Knowledge and Data Gaps of Middle East Respiratory Syndrome Coronavirus (MERS-CoV) in Humans. PLoS Curr. 2013;5.

11. World Health Organization. Middle East respiratory syndrome coronavirus (MERS-CoV) - update. Geneva: World Health Organization; 2014. Available from: http://www.who.int/csr/don/2014_06_13_mers/ en/. Date accessed July 16, 2014.

12. World Health Organization. Middle East respiratory syndrome coronavirus (MERS-CoV) - update. Geneva: World Health Organization; 2014. Available from: http://www.who.int/csr/don/2014_06_26/en/. Date accessed July 16, 2014.

13. Memish ZA, Al-Tawfiq JA, Assiri A, et al. Middle East Respiratory Syndrome Coronavirus Disease in Children. Pediatr Infect Dis J. Epub April 23, 2014.

14. World Health Organization. Middle East Respiratory Syndrome Coronavirus (MERS-CoV). Summary and Literature Update - as of 27 March 2014. Geneva: World Health Organization; 2014. Available from: http://www.who.int/csr/disease/coronavirus_infections/MERS_CoV_ Update_27_March_2014.pdf?ua=1. Date accessed September 11, 2014.

15. Center for Infectious Disease Research and Policy. Gush of MERS cases sparks speculation about causes. Minneapolis: Center for Infectious Disease Research and Policy; 2014. Available from: http://www. cidrap.umn.edu/news-perspective/2014/04/gush-mers-cases-sparksspeculation-about-causes. Date accessed July 18, 2014.

16. Hemida MG, Perera RA, Wang P, et al. Middle East Respiratory Syndrome (MERS) coronavirus seroprevalence in domestic livestock in Saudi Arabia, 2010 to 2013. Euro Surveill. 2013;18(50):20659.

17. Reusken CB, Haagmans BL, Müller MA, et al. Middle East respiratory syndrome coronavirus neutralising serum antibodies in dromedary camels: a comparative serological study. Lancet Infect Dis. 2013;13(10): 859-866. 
18. Reusken CB, Messadi L, Feyisa A, et al. Geographic distribution of MERS coronavirus among dromedary camels, Africa. Emerg Infect Dis. 2014;20(8):1370-1374.

19. Alagaili AN, Briese T, Mishra N, et al. Middle East respiratory syndrome coronavirus infection in dromedary camels in Saudi Arabia. MBio. 2014;5(2):e00884-14.

20. Memish ZA, Al-Tawfiq JA, Makhdoom HQ, et al. Screening for Middle East respiratory syndrome coronavirus infection in hospital patients and their healthcare worker and family contacts: a prospective descriptive study. Clin Microbiol Infect. 2014;20(5):469-474.

21. Mailles A, Blanckaert K, Chaud P, et al; investigation team. First cases of Middle East Respiratory Syndrome Coronavirus (MERS-CoV) infections in France, investigations and implications for the prevention of human-to-human transmission, France, May 2013. Euro Surveill. 2013;18(24). pii: 20502.

22. Health Protection Agency (HPA) UK Novel Coronavirus Investigation team. Evidence of person-to-person transmission within a family cluster of novel coronavirus infections, United Kingdom, Feb 2013. Euro Surveill. 2013;18(11):20427.

23. Pebody RG, Chand MA, Thomas HL, et al. The United Kingdom public health response to an imported laboratory confirmed case of a novel coronavirus in Sep 2012. Euro Surveill. 2012;17(40):20292.

24. World Health Organization. WHO RiskAssessment. Middle East Respiratory Syndrome Coronavirus (MERS-CoV) 24 April 2014. Geneva: World Health Organization; 2014. Available from: http://www.who. int/csr/disease/coronavirus_infections/MERS_CoV_RA_20140424. pdf?ua=1. Date accessed September 11, 2014.

25. Haagmans BL, Al Dhahiry SH, Reusken CB, et al. Middle East respiratory syndrome coronavirus in dromedary camels: an outbreak investigation. Lancet Infect Dis. 2014;14(2):140-145.

26. Perera RA, Wang P, Gomaa MR, et al. Seroepidemiology for MERS coronavirus using microneutralisation and pseudoparticle virus neutralisation assays reveal a high prevalence of antibody in dromedary camels in Egypt, Jun 2013. Euro Surveill. 2013;18(36):pii=20574.

27. Meyer B, Müller MA, Corman VM, et al. Antibodies against MERS coronavirus in dromedary camels, United Arab Emirates, 2003 and 2013. Emerg Infect Dis. 2014;20(4):552-559.

28. Chu DK, Poon LL, Gomaa MM, et al. MERS coronaviruses in dromedary camels, Egypt. Emerg Infect Dis. 2014;20(6):1049-1053.

29. Nowotny N, Kolodziejek J. Middle East respiratory syndrome coronavirus (MERS-CoV) in dromedary camels, Oman, 2013. Euro Surveill. 2014;19(16):20781.

30. Alexandersen S, Kobinger GP, Soule G, Wernery U. Middle East respiratory syndrome coronavirus antibody reactors among camels in Dubai, United Arab Emirates, in 2005. Transbound Emerg Dis. 2014;61(2):105-108.

31. Reusken CB, Ababneh M, Raj VS, et al. Middle East Respiratory Syndrome coronavirus (MERS-CoV) serology in major livestock species in an affected region in Jordan, Jun to Sep 2013. Euro Surveill. 2013;18(50):20662.

32. Corman VM, Jores J, Meyer B, et al. Antibodies against MERS coronavirus in dromedary camels, Kenya, 1992-2013. Emerg Infect Dis. 2014;20(8):1319-1322.

33. Müller MA, Corman VM, Jores J, et al. MERS coronavirus neutralizing antibodies in camels, eastern Africa, 1983-1997. Emerg Infect Dis. Epub August 15, 2014.

34. Memish ZA, Cotten M, Meyer B, et al. Human infection with MERS coronavirus after exposure to infected camels, Saudi Arabia, 2013. Emerg Infect Dis. 2014;20(6):1012-1015.

35. Azhar EI, El-Kafrawy SA, Farraj SA, et al. Evidence for camel-to-human transmission of MERS coronavirus. N Engl J Med. 2014;370(26): 2499-2505.

36. Briese T, Mishra N, Jain K, et al. Middle East respiratory syndrome coronavirus quasispecies that include homologues of human isolates revealed through whole-genome analysis and virus cultured from dromedary camels in Saudi Arabia. MBio. 2014;5(3):e01146-14.
37. Reusken C, Farag E, Jonges M, et al. Middle East respiratory syndrome coronavirus (MERS-CoV) RNA and neutralising antibodies in milk collected according to local customs from dromedary camels, Qatar, Apr 2014. Euro Surveill. 2014;19(23). pii: 20829.

38. MERS-CoV in camels ... [CORRECTED] [webpage on the Internet]. The blog for Virology Down Under; 2014. Available from: http:// virologydownunder.blogspot.com/2014/03/mers-in-camels.html. Date accessed July 15, 2014.

39. World Health Organization. Update on MERS-CoV transmission from animals to humans, and interim recommendations for at-risk groups. Geneva: World Health Organization; 2014. Available from: http://www.who.int/csr/disease/coronavirus_infections/MERS_CoV_ RA_20140613.pdf?ua=1. Date accessed July 14, 2014.

40. Memish ZA, Mishra N, Olival KJ, et al. Middle East respiratory syndrome coronavirus in bats, Saudi Arabia. Emerg Infect Dis. 2013;19(11):1819-1823.

41. Yang L, Wu Z, Ren X, et al. MERS-Related Betacoronavirus in Vespertilio superans Bats, China. Emerg Infect Dis. 2014;20(7):1260-1262.

42. Memish ZA, Zumla AI, Al-Hakeem RF, Al-Rabeeah AA, Stephens GM. Family cluster of Middle East respiratory syndrome coronavirus infections. N Engl J Med. 2013;368(26):2487-2494.

43. World Health Organization. Middle East Respiratory Syndrome Coronavirus, Joint Kingdom of Saudi Arabia/WHO mission. Geneva: World Health Organization; 2013. Available from: http://www.who.int/ csr/disease/coronavirus_infections/MERSCov_WHO_KSA_Mission_ Jun13_.pdf. Date accessed July 14, 2014.

44. Omrani AS, Matin MA, Haddad Q, Al-Nakhli D, Memish ZA, Albarrak AM. A family cluster of Middle East Respiratory Syndrome Coronavirus infections related to a likely unrecognized asymptomatic or mild case. Int J Infect Dis. 2013;17(9):e668-e672.

45. Memish ZA, Cotten M, Watson SJ, et al. Community case clusters of Middle East respiratory syndrome coronavirus in Hafr Al-Batin, Kingdom of Saudi Arabia: a descriptive genomic study. Int $J$ Infect Dis. 2014;23:63-68.

46. Al-Abdallat MM, Payne DC, Alqasrawi S, et al; for the Jordan MERSCoV Investigation Team. Hospital-Associated Outbreak of Middle East Respiratory Syndrome Coronavirus: A Serologic, Epidemiologic, and Clinical Description. Clin Infect Dis. Epub May 14, 2014.

47. Cotten M, Watson SJ, Kellam P, et al. Transmission and evolution of the Middle East respiratory syndrome coronavirus in Saudi Arabia: a descriptive genomic study. Lancet. 2013;382(9909):1993-2002.

48. ProMED-mail. MERS-COV - Eastern Mediterranean (42): Saudi Arabia, Genome sequencing, Jeddah outbreak. Brookline, MA: International Society for Infectious Diseases; 2014. Available from: http://www. promedmail.org/direct.php?id=2432140. Date accessed July 15, 2014.

49. World Health Organization. WHO concludes MERS-CoV mission in Saudi Arabia. Geneva: World Health Organization; 2014. Available from: http://www.emro.who.int/media/news/mers-cov-missionsaudi-arabia.html. Date accessed July 15, 2014.

50. European Centre for Disease Prevention and Control. Severe respiratory disease associated with Middle East respiratory syndrome coronavirus (MERS-CoV). Stockholm: European Centre for Disease Prevention and Control; 2014. Available from: http://www.ecdc.europa.eu/en/publications/ Publications/Middle-East-respiratory-syndrome-coronavirus-risk-assessment-25-April-2014.pdf. Date accessed July 15, 2014.

51. Memish ZA, Zumla AI, Assiri A. Middle East respiratory syndrome coronavirus infections in health care workers. $N$ Engl J Med. 2013;369(9):884-886.

52. Centers for Disease Control and Prevention. Middle East Respiratory Syndrome (MERS). Atlanta: Centers for Disease Control and Prevention; 2014. Available from: http://www.cdc.gov/CORONAVIRUS/MERS/ INDEX.HTML. Date accessed June 15, 2014.

53. Bermingham A, Chand MA, Brown CS, et al. Severe respiratory illness caused by a novel coronavirus, in a patient transferred to the United Kingdom from the Middle East, September. Euro Surveill. 2012;17(40):20290. 
54. National Institute for Public Health and the Environment. The MERScoronavirus in The Netherlands. Bilthoven: National Institute for Public Health and the Environment; 2014. Available from: http:// www.rivm.nl/en/Documents_and_publications/Common_and_Present/ Newsmessages/2014/The_MERS_coronavirus_in_the_Netherlands. Date accessed June 29, 2014.

55. European Centre for Disease Prevention and Control. Epidemiological update: Middle East respiratory syndrome coronavirus (MERS-CoV). Available from: http://www.ecdc.europa.eu/en/press/news/_layouts/ forms/News_DispForm.aspx?List=8db7286c-fe2d-476c-913318ff4cb1b568\&ID=994. Date accessed July 16, 2014.

56. Centers for Disease Control and Prevention. Middle East Respiratory Syndrome. Atlanta: Centers for Disease Control and Prevention; 2014 Available from: http:/www.cdc.gov/CORONAVIRUS/MERS/US.html. Date accessed July 16, 2014.

57. Brosseau LM, Jones R. COMMENTARY: Protecting health workers from airborne MERS-CoV - learning from SARS. Minneapolis: Center for Infectious Disease Research and Policy; 2014. http://www. cidrap.umn.edu/news-erspective/2014/05/commentary-protectinghealth-workers-airborne-mers-cov-learning-sars. Date accessed July 15,2014

58. Memish ZA, Zumla A, Al-Tawfiq JA. How great is the risk of Middle East respiratory syndrome coronavirus to the global population? Expert Rev Anti Infect Ther. 2013;11(10):979-981.
59. ProMED-mail. Novel coronavirus - Eastern Mediterranean (03): Saudi comment. Brookline, MA: International Society for Infectious Diseases; 2014. Available from: http://www.promedmail.org/direct. php?id=1540011. Date accessed September 11, 2014.

60. Gautret P, Charrel R, Belhouchat K, et al. Lack of nasal carriage of novel corona virus (HCoV-EMC) in French Hajj pilgrims returning from the Hajj 2012, despite a high rate of respiratory symptoms. Clin Microbiol Infect. 2013;19(7):E315-E317.

61. Memish ZA, Assiri A, Almasri M, et al. Prevalence of MERS$\mathrm{CoV}$ nasal carriage and compliance with the Saudi health recommendations among pilgrims attending the 2013 Hajj. J Infect Dis. 2014;210(7):1067-1072.

62. Centers for Disease Control and Prevention. Interim infection prevention and control recommendations for hospitalized patients with Middle East respiratory syndrome coronavirus (MERS-CoV). Atlanta: Centers for Disease Control and Prevention; 2014. Available from: http://www.cdc. gov/coronavirus/mers/infection-prevention-control.html. Date accessed June 28, 2014.

63. Memish ZA, Al-Tawfiq JA, Assiri A. Hospital-associated Middle East respiratory syndrome coronavirus infections. $N$ Engl J Med. 2013;369(18):1761-1762.

64. Memish ZA, Al-Rabeeah AA. Health conditions of travellers to Saudi Arabia for the pilgrimage to Mecca (Hajj and Umra) for 1434 (2013). J Epidemiol Glob Health. 2013;3(2):59-61.
Infection and Drug Resistance

\section{Publish your work in this journal}

Infection and Drug Resistance is an international, peer-reviewed openaccess journal that focuses on the optimal treatment of infection (bacterial, fungal and viral) and the development and institution of preventive strategies to minimize the development and spread of resistance. The journal is specifically concerned with the epidemiology of antibiotic

\section{Dovepress}

resistance and the mechanisms of resistance development and diffusion in both hospitals and the community. The manuscript management system is completely online and includes a very quick and fair peerreview system, which is all easy to use. Visit http://www.dovepress.com/ testimonials.php to read real quotes from published authors. 